\title{
RANCANG BANGUN E-COMMERCE PADA TOKO KERUDUNG NURI COLLECTION BERBASIS CUSTOMER RELATIONSHIP MANAGEMENT
}

\author{
Linda Durotul Ummah \\ Fakultas Ilmu Komputer Universitas Kuningan \\ Jalan Tjut Nyak Dhien No. 36 A Cijoho Kuningan Jawa Barat 45513Telepon (0232) 2875097 \\ lindadurotul@gmail.com
}

E-commerce merupakan suatu kontak transaksi perdagangan antara penjual dan pembeli dengan menggunakan media elektronik. Keuntungan yang diperoleh dengan menggunakan transaksi melalui e-commerce adalah untuk meningkatkan pendapatan dengan menggunakan penjualan online yang biayanya lebih murah. E-commerce pada toko kerudung Nuri Collection ini berbasis Customer Relationship Management (CRM), yaitu penerapan Customer Relationship Management (CRM) secara tidak langsung dikatakan sebagai pengkomputerisasian data pelanggan. Hal ini dimaksudkan agar perusahaan mengetahui apa yang menjadi kebutuhan dan keinginan pelanggan sehingga dapat terjalin hubungan yang baik dengan pelanggan. Tujuan penelitian ini untuk mengetahui pendapat konsumen tentang Customer Relationship Management (CRM) yang dilaksanakan perusahaan, menganalisis loyalitas konsumen terhadap produk Nuri Collection. E-commerce yang dibangun ini menggunakan metode pengembangan sistem Waterfall, dengan alat bantu perancangan sistem berupa Flowmap, DFD, diagram Konteks, ERD. Sedangkan dalam pembuatan e-commerce ini penulis menggunakan bahasa pemrograman PHP dan MYSQL sebagai database.

Kata Kunci : E-commerce, CRM, PHP

E-commerce is a contact of trade transactions between seller and buyer by using electronic media. The advantage gained by using transactions through e-commerce is to increase revenue by using online sales that cost less. E-commerce on Nuri Collection's shop based veil Customer Relationship Management (CRM), namely the application of Customer Relationship Management (CRM) is not directly said as a computerized data customer. It is intended that the company knows what the needs and wants of customers so that it can establish a good relationship with customers. The purpose of this research is to know consumer opinion about Customer Relationship Management (CRM) which conducted by company, analyze consumer loyalty to Nuri Collection product. Ecommerce is built using Waterfall system development method, with a system design tools such as Flowmap, DFD, Context diagram, ERD. While in making this e-commerce writer use programming language PHP and MYSQL as database.

Keywords: E-commerce, CRM, PHP

\section{PENDAHULUAN}

\subsection{Latar Belakang}

Dalam era globalisasi ini, tingkat penggunaan teknologi semakin lama semakin meningkat. Begitu juga dengan tingkat penggunaan internet. Dalam beberapa waktu terakhir ini, begitu merebaknya media internet dimanamana, khususnya di Indonesia. Internet tidak hanya berpengaruh pada aktivitas penduduk sehari-hari tapi juga berpengaruh pada aktivitas bisnis. Kehadiran internet telah memperkokoh keyakinan akan pentingnya peranan teknologi dalam pencapaian tujuan finansial perusahaan melalui modifikasi dan efesiensi proses bisnis, yaitu dengan memanfaatkan E-Commerce.

E-Commerce atau disebut juga perdagangan elektronik merupakan 
aktivitas yang berkaitan dengan pembelian, penjualan, pemasaran barang ataupun jasa dengan memanfaatkan sistem elektronik seperti internet ataupun jaringan komputer. $E$ Commerce juga melibatkan aktivitas yang berhubungan dengan proses transaksi elektronik seperti transfer dana elektronik, pertukaran data elektronik dan lain sebagainya. Melalui sistem penjualan berbasis web, perusahaan memiliki peluang yang sama agar dapat bersaing dan berhasil berbisnis di dunia maya. (Barkatulla, 2005).

Di dalam dunia bisnis persaingan menjadi bagian yang tidak dapat ditoleransi lagi kini persaingan usaha semakin ketat, baik itu dalam hal pemasaran, pelayanan, produksi, dan publikasi semua berlomba dalam mencapai target usahanya yaitu untuk meningkatkan omset dan tetap menjaga eksistensi perusahaan untuk jangka waktu yang panjang.

Pelanggan merupakan aset bagi setiap toko penjualan kerudung. Nuri Collection merupakan salah satu toko kerudung yang memiliki banyak pelanggan. Oleh karena itu toko kerudung Nuri Collection berusaha untuk mempertahankan loyalitas pelanggannya, karena efek yang dapat ditimbulkan dari loyalitas pelanggan adalah pembelian yang berulang, kesediaan pelanggan untuk merekomendasikan kepada orang lain. Seiring berkembangnya Toko Kerudung Nuri Collection permintaan konsumen akan barangpun semakin meningkat saat ini. Sistem yang ada di toko kerudung ini pemasaran hanya menggunakan Blackberry Messenger, dan Whatsapp. Promosi barang masih menggunakan banner tidak adanya sarana penjualan jarak jauh yang bisa mempermudah dalam memperluas wilayah pemasaran. Toko Kerudung Nuri Collection ingin bisnisnya dapat berkembang dalam menggunakan salah satu strategi bisnis yang berorientasi pada pelanggan. Perusahaan ingin menjaga hubungan dengan pelanggannya sehingga pelanggan tetap loyal dan sisi lain juga mendapatkan pelanggan baru dari waktu ke waktu. Maka dari itu Rancang bangun E-Commerce yang akan penulis buat yaitu dengan metode CRM. Sesuai dengan tujuan umum CRM adalah menciptakan dan mempertahankan suatu hubungan yang baik dengan pelanggan dan mengurangi kemungkinan pelanggan berpindah ke produk pesaing. Berdasarkan pemaparan diatas, maka penulis tertarik untuk melakukan penelitian dalam bentuk skripsi dengan judul Yaitu " Rancang Bangun ECommerce Pada Toko Kerudung Nuri Collection Berbasis Customer Relationship Management ".

\subsection{Rumusan Masalah}

Berdasarkan latar belakang yang telah diuraikan diatas, penulis merumuskan masalah yang dibahas dalam penelitian skripsi ini sebagai berikut :

1. Bagaimana cara merancang $E$ Commerce berbasis CRM pada Toko Kerudung Nuri Collection.

2. Bagaimana implementasi Operasional CRM pada Toko Kerudung Nuri Collection.

1.3 Batasan Masalah

Untuk menghindari kesalahpahaman dan meluasnya pembahasan, maka penulis membatasi masalah dalam penelitian skripsi ini sebagai berikut :

1. Penerapan CRM yang dibangun pada Nuri Collection termasuk model Operasional CRM yang berfokus pada otomatisasi pemasaran dan pelayanan pelanggan.

2. Pelanggan harus mendaftar sebagai member untuk dapat melakukan transaksi pembelian. 
3. Pelanggan dapat melakukan pemesanan kerudung yang tersedia pada katalog produk.

4. Proses pembayaran transaksi melalui transfer bank pada rekening yang telah ditetapkan di Website ECommerce.

5. Pelanggan dapat melakukan konfirmasi pembayaran.

6. Sistem ini meliputi Frequently Ask Questions (FAQ) untuk menampilkan laporan kritik dan saran, pertanyaan dari pelanggan.

7. Menampilkan info terbaru atau promosi terbaru.

8. Bahasa pemrograman yang digunakan adalah PHP dan menggunakan MySQL sebagai Database Mangement System (DBMS).

\section{METODOLOGI PENELITIAN}

2.1 Metode Pengumpulan Data

Metode pengumpulan data yang diperlukan untuk mendapatkan datadata diatas adalah sebagai berikut :

\section{Metode Observasi}

Metode Observasi merupakan teknik mendapatkan data primer dengan cara mengamati langsung obyek datanya. Penulis yaitu dengan cara datang langsung ke Toko Kerudung Nuri Collection untuk mengamati proses penjualan yang sedang berjalan saat ini, guna mendapatkan data secara langsung pada objek yang diteliti sebagai bahan untuk menulis penelitian.

2. Metode Wawancara

Metode Wawancara adalah pendekatan yang berhubungan langsung sumber data dan terjadi proses komunikasi untuk mendapatkannya. Dengan wawancara data yang diperoleh akan lebih mendalam, karena mampu menggali pemikiran atau pendapat secara detail. Proses wawancara dilakukan secara langsung dengan pihak yang terkait yang berhubungan dengan informasi Toko Kerudung Nuri Collection agar proses yang dibuat sesuai dengan kebutuhan.

3. Metode Studi Pustaka

Metode kepustakaan dilakukan dengan cara membaca dan mempelajari referensi-referensi, baik yang bersifat online (internet) ataupun yang offline (literature, textbook, jurnal, surat kabar, artikel-artikel yang berhubungan dengan penelitian ini sehingga data yang dibutuhkan dalam penelitian ini bisa terpenuhi.

\subsection{Metode Pengembangan Sistem}

Metode perancangan yang digunakan dalam penulisan skripsi ini melalui pendekatan metode Software Development Life Cycle (SDLC)/waterfall karena dalam penelitian ini perlu adanya pendekatan secara sistematis dan urut mulai dari level kebutuhan sistem lalu menuju ke tahap analisis, desain, coding, testing dan maintenance. Model waterfall dapat dilihat pada gambar 1.1.

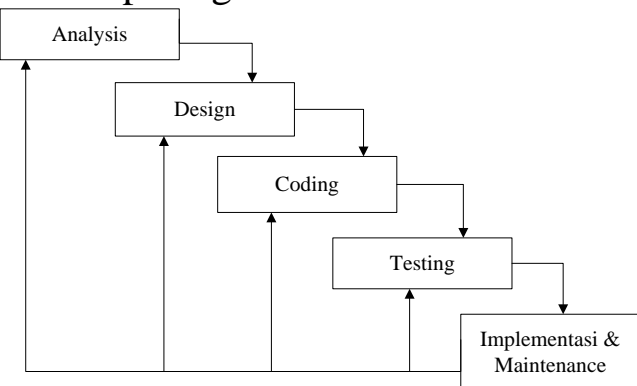

Sumber : Roger S.Pressman, 2002 Gambar 1. Model Waterfall

1. Analysis

Proses menganalisis dan mengumpulkan kebutuhan sistem yang sesuai dengan informasi tingkah laku, unjuk kerja, dan antar muka (interface) yang diperlukan. 
Pengembang dan pemakai bertemu untuk melakukan analisa terhadap program yang akan dibuat.

2. Design

Dalam tahap ini penulis akan merancang desain dan model rancang bangun yang akan dikembangkan hasil dan analisa pada tahap sebelumnya. Model proses yang akan digunakan dalam perancangan web ini adalah model data terstruktur yaitu menggunakan Flowmap sebagai model proses bisnis, sedangkan untuk menggambar proses fungsional menggunakan Data Flow Diagram (DFD) serta Entity Relationship Diagram (ERD) sebagai model relasi data.

3. Coding

Pengkodean (coding) merupakan proses menterjemah desain ke dalam suatu bahasa yang bisa dimengerti oleh komputer. Dilakukan oleh programmer yang akan menterjemahkan transaksi yang diminta oleh user. Tahapan inilah yang merupakan tahapan secara nyata dalam mengerjakan suatu sistem.

Dalam merancang web ini akan menggunakan bahasa pemrograman PHP dan database MySQL.

4. Testing

Proses pengujian berfokus pada logika internal software, memastikan bahwa semua pernyataan sudah diuji, dan pada eksternal fungsional yaitu mengarahkan pengujian untuk menemukan kesalahan-kesalahan dan memastikan bahwa input yang dibatasi akan memberikan hasil aktual yang sesuai dengan hasil yang dibutuhkan. Penulis akan melakukan pengujian sistem dengan menggunakan Black Box dan White Box Testing.

5. Impelementasi \& Maintenance

Proses yang terakhir yaitu implementasi dan maintenance, program yang telah dibuat di implementasikan, dan pemeliharaan suatu software diperlukan, termasuk didalamnya adalah pengembangan, karena software yang dibuat tidak selamanya hanya seperti itu.

\subsection{E-Business}

E-business adalah E-business (Inggris: Electronic Business, atau "Ebusiness") dapat diterjemahkan sebagai kegiatan bisnis yang dilakukan secara otomatis dan semiotomatis dengan menggunakan sistem informasi komputer. Istilah yang pertama kali diperkenalkan oleh Lou Gerstner, seorang CEO perusahaan IBM ini, sekarang merupakan bentuk kegiatan bisnis yang dilakukan dengan menggunakan teknologi Internet. Ebusiness memungkinkan suatu perusahaan untuk berhubungan dengan sistem pemrosesan data internal dan eksternal mereka secara lebih efisien dan fleksibel. E-business juga banyak dipakai untuk berhubungan dengan suplier dan mitra bisnis perusahaan, serta memenuhi permintaan dan melayani kepuasan pelanggan secara lebih baik.

2.4 E-Commerce

E-commerce merupakan suatu istilah yang sering digunakan atau didengar saat ini yang berhubungan dengan internet, dimana tidak seorangpun yang mengetahui jelas pengertian dari e-commerce tersebut. Berikut akan dipaparkan pengertian $e$ commerce menurut para ahli :

a) Menurut McLeod Pearson (2008 : 59) Perdagangan elektronik atau yang disebut juga $e$ commerce, adalah penggunaan 
jaringan komunikasi dan komputer untuk melaksanakan proses bisnis. Pandangan populer dari e-commerce adalah penggunaan internet dan komputer dengan browser Web untuk membeli dan menjual produk.

b) Menurut Shely Cashman (2007: 83) E-commerce atau kependekan dari elektronik commerce (perdagangan secara electronic), merupakan transaksi bisnis yang terjadi dalam jaringan elektronik, seperti internet. Siapapun yang dapat mengakses komputer, memiliki sambungan ke internet, dan memiliki cara untuk membayar barang-barang atau jasa yang mereka beli, dapat berpartisipasi dalam e-commerce.

c) Menurut Jony Wong (2010 : 33) pengertian dari electronic commerce adalah pembelian, penjualan dan pemasaran barang serta jasa melalui sistem elektronik. Seperti radio, televisi dan jaringan computer atau internet.

d) Triton (2006), menjelaskan bahwa e-commerce (electronic commerce) sebagai perdagangan elektronik dimana untuk transaksi perdagangan baik membeli maupun menjual dilakukan melalui elektronik pada jaringan internet. Keberadaan e-commerce sendiri dalam internet dapat dikenali melalui adanya fasilitas pemasangan iklan, penjualan, dan service support terbaik bagi seluruh pelanggannya dengan menggunakan sebuah toko online berbentuk web yang setiap harinya beroperasi selama 24 jam.

Jadi pengertian $e$ -
commerce adalah proses
transaksi jual beli yang
dilakukan melalui internet
dimana website digunakan
sebagai wadah untuk melakukan
proses tersebut.

2.5 Customer Relationship Management (CRM)

Customer Relationship Management (CRM) menurut Kalakota dan Robinson (2001), $\mathrm{CRM}$ adalah fungsi terintegrasi strategi penjualan, pemasaran, dan pelayanan yang bertujuan untuk meningkatkan pendapat dari kepuasan pelanggan.

Menurut Buttle (Diana dan Tjiptono 2007 : 190), adalah strategi bisnis inti yang mengintegrasikan proses dan fungsi internal serta jejaring eksternal untuk menciptakan dan menyampaikan nilai bagi pelanggan sarana dalam rangka mendapatkan laba. CRM ditunjang dengan data pelanggan berkualitas tinggi dan difasilitasi teknologi.

\section{HASIL DAN PEMBAHASAN}

3.1 Gambaran Umum Toko Kerudung Nuri Collection

Toko kerudung Nuri Collection merupakan usaha yang bergerak di bidang penjualan kerudung. Toko kerudung Nuri Collection menjual berbagai macam kerudung secara lengkap degan gaya dan model yang up to date. Toko kerudung Nuri Collection dikelola oleh Ibu Enung Nuraeni dengan jumlah karyawan 1 orang.

\subsection{Analisis Masalah}

Permasalahan yang ada di Toko Kerudung Nuri Collection ini adalah belum adanya sistem 
JURNAL NUANSA INFORMATIKA

Volume 12 Nomor 2, Juli 2018

pemasaran kerudung, sehingga nilai jual dan promosi kepada pelanggan / konsumen sangat kecil. Untuk itu dengan adanya sistem ini diharapkan Toko Kerudung Nuri Collection mampu memasarkan beraneka macam kerudung yang ada, serta semua pelangga dapat melihat dan tertarik untuk membeli kerudung ini, sehingga penjualan dari kerudung ini akan meningkat dengan baik.

Adapun sistem yang sedang berjalan di toko kerudung Nuri Collection dapat dilihat pada gambar 3.1.

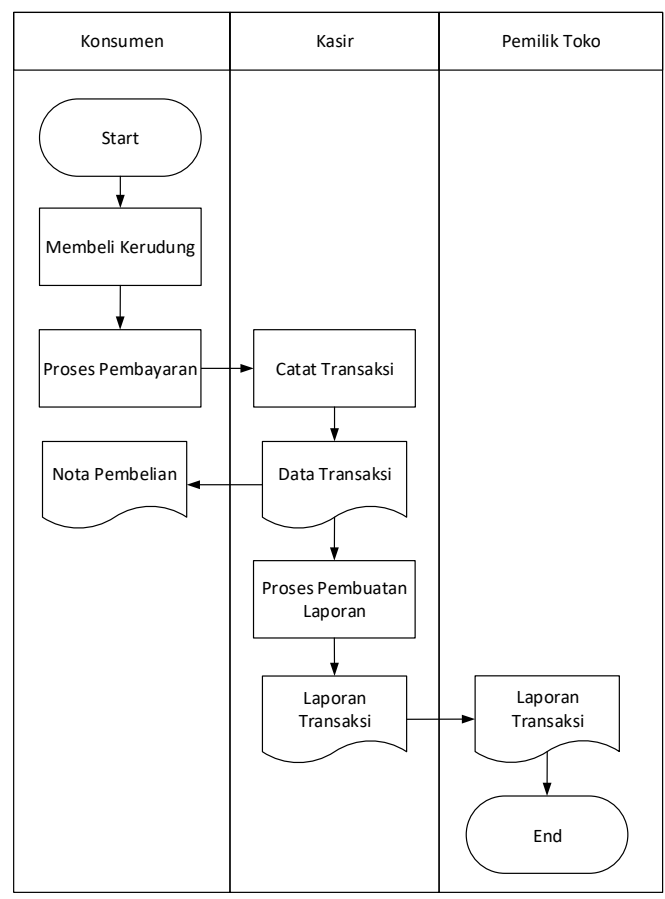

Gambar 2. Flowmap Sistem

Berjalan
p-ISSN : 1858-3911, e-ISSN : 2614-5405

https://journal.uniku.ac.id/index.php/ilkom

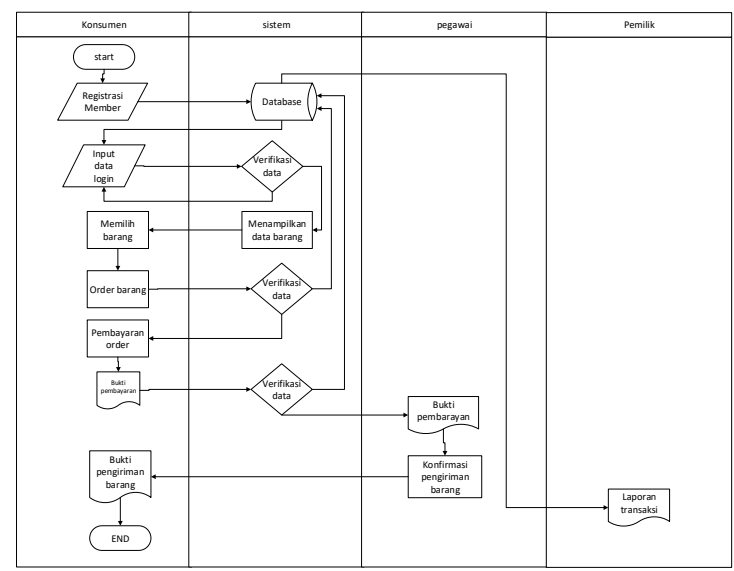

Gambar 3. Flowmap Sistem Usulan

1. Diagram Konteks

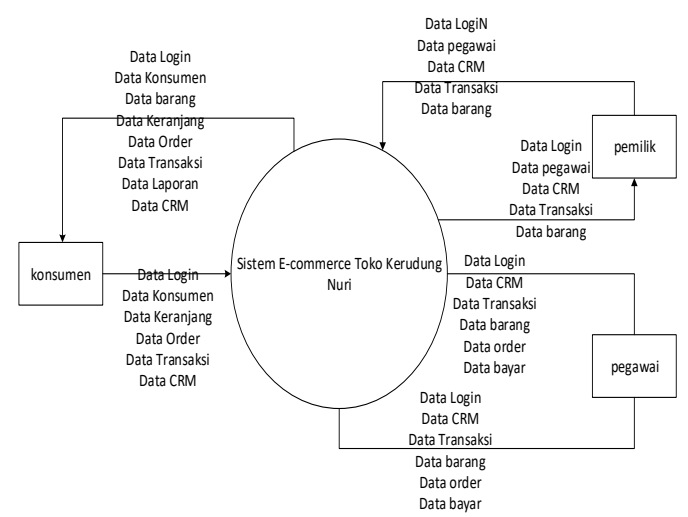

Gambar 4. Diagram Konteks

2. Data Flow Diagram (DFD) Level 0

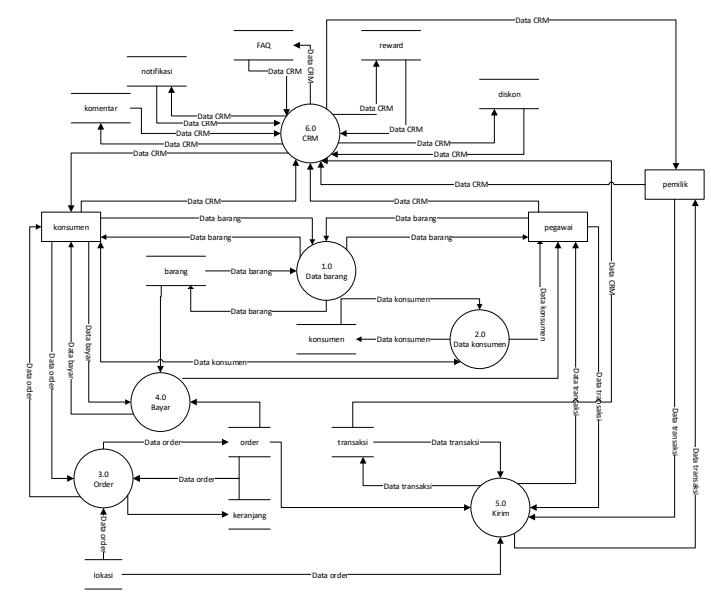

Gambar 5. DFD Level 0 
3. ERD

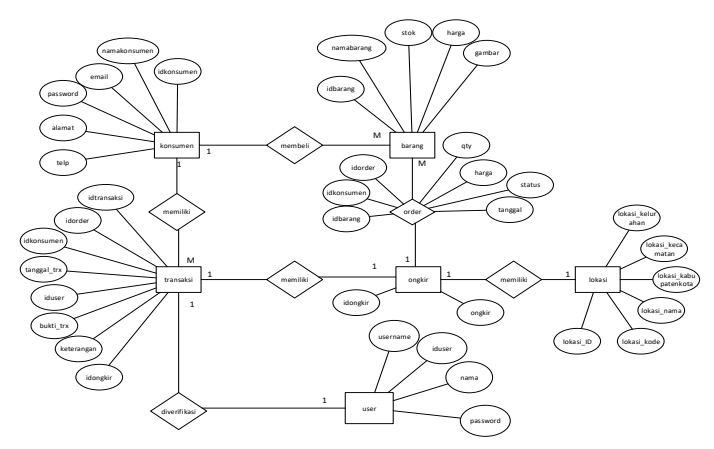

Gambar 6. ERD

\subsection{Antar Muka Program}

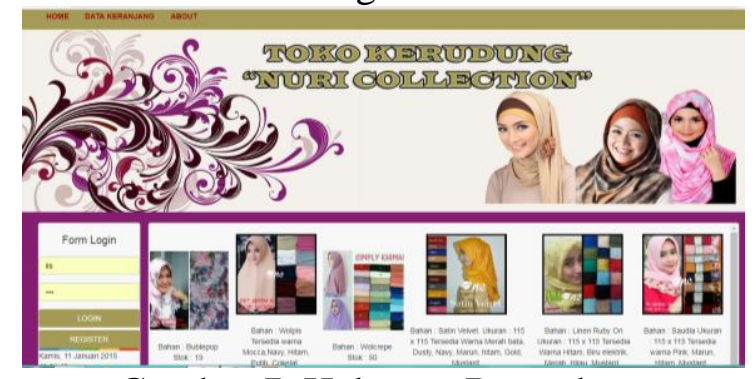

Gambar 7. Halaman Beranda

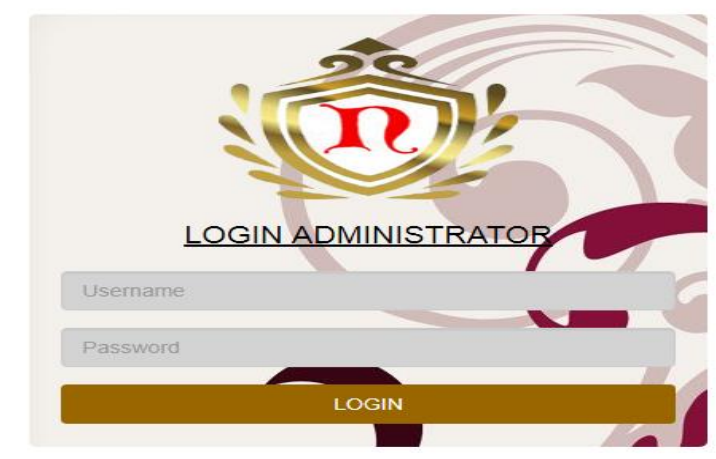

Gambar 8. Form Login Admin

\section{KESIMPULAN}

Berdasarkan hasil penelitian pada bab-bab sebelumnya, maka dapat diambil kesimpulan bahwa

1. Dengan dibangunnya sistem penjualan dan pemesanan online, pelanggan dapat memperoleh informasi mengenai produk-produk yang dijual oleh toko kerudung Nuri Collection dan mempermudah pelanggan dalam melakukan transaksi pembelian tanpa harus datang langsung ke toko tersebut.

2. Dengan adanya sistem penjualan dan pemesanan online yang didukung dengan penerapan strategi Operasional CRM di Toko kerudung Nuri Collection ini dapat mengenal pelanggan dengan baik. Sistem ini diharapkan dapat memfasilitasi toko kerudung Nuri Collection dalam pelayanan pelanggan, promosi, sampai mendapatkan pelanggan baru. Sehingga mempermudah toko kerudung Nuri Collection dalam membangun ikatan yang lebih kuat dengan para pelanggan yang bertujuan untuk menciptakan loyalitas pelanggan.

\section{SARAN}

Dalam perancangan dan pembangunan sistem penjualan dan pemesanan online ini, penulis menyadari bahwa penulisan skripsi ini masih banyak terdapat kekurangan yang kiranya dapat diperbaiki dalam penelitian selanjutnya. Oleh karena itu, penulis memberikan saran sebagai berikut :

1. Pengembangan e-commerce dengan menerapkan strategi analytical CRM ataupun Collaborative CRM untuk meningkatkan hubungan dengan pelanggan dimasa sekarang dan dimasa yang akan datang. 
2. Untuk penegembangan sistem, maka penulis mengusulkan pembayaran transaksi pembelian tidak hanya melalui transfer antar bank, tetapi dapat dikembangkan juga melalui paypal dan kartu kredit dengan bekerja sama antar pihak bank yang bersangkutan.

\section{DAFTAR PUSTAKA}

Arief M. Rudyanto "Pemrograman Web dinamis menggunakan PHP dan $M y S Q L$ " Andi Offset, Yogyakarta.

Nugroho A, "E-Commerce Memahami Perdagangan Dunia Maya". Bandung : Informatika.

Ovi Dyantika, Mira Afrina dan Ali Ibrahim, "Penerapan Customer Relationship Management (CRM) Berbasis Web (Studi Kasus Pada Sistem Informasi Pemasaran di Toko YEN-YEN)", 2012.[Online]

Pressman, roger (2000) "Rekayasa Perangkat Lunak Pendekatan Praktisi" Yogyakarta.

Prof. Jogiyanto HM., Akt., MBA,. Ph.D (2008) "Metodologi Penelitian Sistem Informasi" Yogyakarta : Andi

Sofana, I. (2013) "Membangun Jaringan Komputer”. Bandung Informatika.

Sukmawantoro, Alur. "Jurnal Rancang Bangun e-CRM pada Toko Pasar Murah Solo".

Sutabri, T.(2012) "Analisis Sistem Informasi”. Yogyakarta : Andi.

Sutedjo Dharma Oetomo, B.(2006) "Perencanaan

Pengembangan Sistem Informasi". Yogyakarta : Andi.

Wijayanti, Teti dan I. Azhari, "Pengembangan Customer Relationship Management
Berbasis Web pada Griya Muslim Flora”, 2011. [Online].

Citra Aris Wisuda, "Makalah EBusiness (Electronic Business)" 2013.

http://eprints.radenfatah.ac.id/153/2/BA B\%20II.pdf (rancang bangun) http://elib.unikom.ac.id/files/disk1/575/j bptunikompp-gdl-widyahardh28737-9-unikom_w-i.pdf (ecomm)

http://proposal\%20skripsi/SKRIPSI/Jur nal_RiaApriyaniDevina_Analisisd anRancangBangun.pdf

http://www.candra.web.id/2012/04/09/e book-membangun-ecommercedengan-php-mysql 